\title{
Common mental disorders and patient-reported swallowing disorders following total laryngectomy
}

\author{
Emykaelly Kauanne Lima Batista ${ }^{1}$ \\ https://orcid.org/0000-0002-2746-1136 \\ Jaims Franklin Ribeiro Soares ${ }^{2}$ \\ https://orcid.org/0000-0003-3389-5931 \\ Giorvan Anderson dos Santos Alves ${ }^{2}$ \\ https://orcid.org/0000-0003-1619-0139 \\ Luciane Spinelli de Figueiredo Pessoa ${ }^{2}$ \\ https://orcid.org/0000-0003-3518-5060 \\ Wagner Teobaldo Lopes de Andrade ${ }^{2}$ \\ https://orcid.org/0000-0002-8600-2327 \\ Vivian Lisboa de Lucena ${ }^{3}$ \\ https://orcid.org/0000-0003-3841-3372 \\ Leandro Pernambuco ${ }^{2}$ \\ https://orcid.org/0000-0001-6246-9769
}

Hospital Universitário Lauro Wanderley, Universidade Federal da Paraíba - UFPB, João Pessoa, Paraíba, Brasil.

Universidade Federal da Paraíba - UFPB, Departamento de Fonoaudiologia, João Pessoa, Paraíba, Brasil.

Hospital Napoleão Laureano, João Pessoa, Paraíba, Brasil.

Conflict of interests: Nonexistent

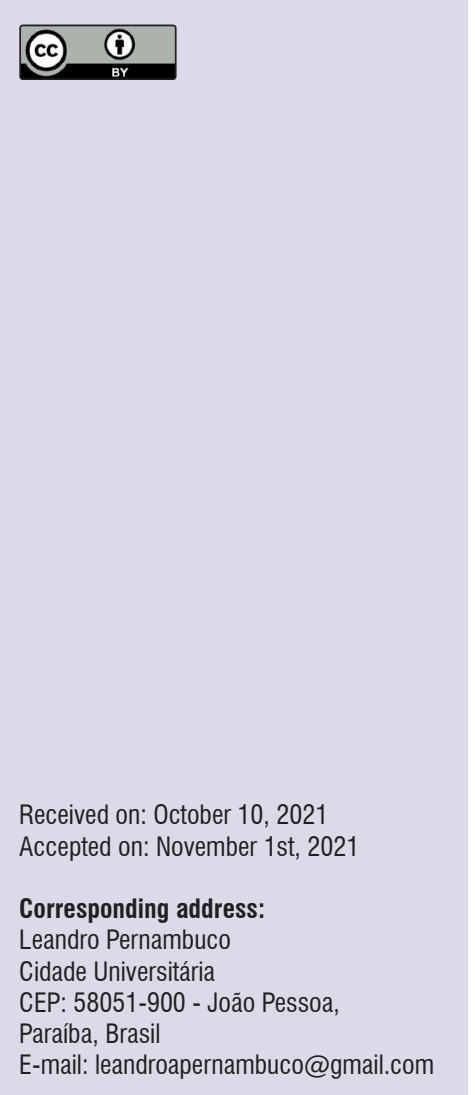

\section{ABSTRACT}

Purpose: the aim of this study was to analyze the relationship between patient-reported swallowing disorders and common mental disorders after total laryngectomy.

Methods: fourteen patients of both genders and aged $66 \pm 8.63$ years were assessed after total laryngectomy. They were all asked about the perception of swallowing disorders and answered the Self-Reporting Questionnaire. Patients with swallowing complaints also answered the MD Anderson Dysphagia Inventory. The mean difference between groups was evaluated using the Mann-Whitney test, with a significance level of $5 \%$.

Results: the median of Self-Reporting Questionnaire total score was 3.00 [interquartile range: $0.00-5.00]$ and did not reflect the presence of common mental disorders. Five volunteers (35.7\%) self-reported swallowing disorders and had a worse, although not significant $(p=0.15)$, performance on the Self-Reporting Questionnaire. The MD Anderson Dysphagia Inventory indicated a limitation in the quality of life, with a greater impact of swallowing disorders in the emotional domain [median = 53.30; interquartile range: 33.30-74.95].

Conclusion: common mental disorders are not related to patient-reported swallowing disorders following total laryngectomy. However, patients with swallowing complaints had a negative impact on their quality of life, especially in the emotional domain.

Keywords: Deglutition Disorders; Laryngeal Neoplasms; Laryngectomy; Mental Disorders; Patient Reported Outcome Measures 


\section{INTRODUCTION}

Total laryngectomy (TL) corresponds to the entire removal of the larynx $x^{1}$, and although this implies in a definitive dissociation between the digestive and respiratory tracts, postoperative anatomical impairments can affect oropharyngeal swallowing because the elevation of the larynx is eliminated and the propulsion of the tongue base is decreased, leading to a rupture of the constricting musculature of the pharynx, an increase in pharyngeal transit time, the presence of pharyngeal residues and a decrease in esophageal peristalsis ${ }^{2-5}$. Other pathophysiological aspects can also compromise swallowing after TL such as pseudodiverticulum, fistualization, stenosis, fibrosis, prosthesis leakage and gastroesophageal reflux $x^{6}$, in addition to sensory and motor impairment of the laryngeal nerves that innervate the pharyn $x^{7}$.

TL dysphagia occurs in approximately $90 \%$ of the cases $^{5}$ and results in prolonged meals, dietary limitations, weight loss, malnutrition, decreased psychological well-being, suffering and impairment in social interactions ${ }^{4,8}$. Being able to swallow is the third major concern of patients diagnosed with laryngeal cancer in relation to treatment of the disease, only after the cure of cancer and the expectation of living as long as possible ${ }^{9}$. Swallowing disorders following total laryngectomy can lead the patient to eating alone or losing the pleasure to eat, which can lead to impairment in social function and a decrease in quality of life ${ }^{10-12}$.

Therefore, it is understood that dysphagia can restrict an individual's relationship with their daily life, which allows us to assume that psychiatric disorders such as Common Mental Disorders (CMD) might emerge. The intensity and chronicity of CMD are related to developing diseases such as anxiety and depression ${ }^{10-14}$, which is why CMD screening is important in patients with swallowing complaints, especially in cases associated with head and neck cancer in which there is a markedly greater risk of psychological distress and worse quality of life ${ }^{15}$.

A mental disorder is a syndrome characterized by a clinically significant disturbance in cognition, emotional regulation, or in behavior of an individual that reflects dysfunction in their psychological, biological, or developmental processes underlying mental functioning, and which are often associated with significant distress or disability affecting social, occupational, or other important activities ${ }^{16}$. The concept of CMD represent cases with non-psychotic symptoms such as insomnia, fatigue, irritability, forgetfulness, difficulty concentrating and somatic complaints which lead to functional disability ${ }^{17,18}$.

Previous studies evaluated the relationships between surgeries for head and neck cancer and specific psychological impairment such as anxiety, depression and stress ${ }^{10-15,19,20}$. However, even though there are signs that complaints of dysphagia in total laryngectomized patients are associated with impairments in mental health ${ }^{21}$, the relationship between CMD and patient-reported swallowing outcomes in these patients is unknown.

After TL, swallowing disorders with solid foods, feeling the food stuck in the throat and needing multiple swallows decreases quality of life ${ }^{5}$. Therefore, it is assumed that the potential psychological suffering caused by swallowing disorders improve emotional imbalance capable of interfering in self-confidence and producing a feeling of incapacity, even when the oncological disease is already controlled 22 .

Considering that after total laryngectomy the patients are usually accompanied by interprofessional health teams, it is important to understand the possible relationship between CMD and swallowing complaints, as well as the impact of swallowing disorders on quality of life. This investigation enables expanding the attention scope of the health of this group of patients when approaching both functional and psychological aspects, thus contributing to a more comprehensive and effective health care, including benefitting the quality of life.

Therefore, the aim of this study was twofold: (a) to analyze the relationship between patient-reported swallowing disorders and CMD after $\mathrm{TL}$, and (b) to explore the impact of swallowing disorders on the quality of life.

\section{METHODS}

This is a cross-sectional study approved by the Ethics and Research Committee on Human Beings of the Health Sciences Center of the Federal University of Paraíba, Brazil, under No. 2.190.942/2017, according to Resolution 466/2012 of the National Health Council (CNS) and according to the World Medical Association Declaration of Helsinki. All the participants signed a Free and Informed Consent Form (ICF) before being submitted to the research procedures. 


\section{Sample}

The study included individuals with 18 years of age and older of both sex, submitted to TL with or without neck dissection, with or without adjuvant radiotherapy and/or chemotherapy. Exclusion criteria were: current radiotherapy, chemotherapy or concurrent chemoradiotherapy treatment; no oral intake at the data collection time; neurological, neuromuscular or neurodegenerative disorders which were self-reported or reported in the medical record; other surgeries in the head and neck area.

The convenience sample was obtained among the TL support group of the Napoleão Laureano Hospital, a tertiary oncology hospital in João Pessoa, Paraiba, Brazil. The sample consisted of fourteen individuals with mean age of $66 \pm 8.63$ years, where the majority were males $(n=12,85.7 \%)$, treated for squamous cell carcinoma in the larynx $(n=11 ; 78.6 \%)$ for a mean time of $8.36 \pm 4.85$ years.

\section{Instruments}

The Brazilian Portuguese version of the Self-Reporting Questionnaire (SRQ - 20) $)^{23,24}$ was applied. The SRQ-20 is an instrument for CMD screening, consisting of 20 questions for detecting symptoms such as level of suspicion (absent/present) of any mental disorder, however, without determination of a specific diagnosis. The SRQ-20 presents four domains classified as anxious depressive mood (questions 01 to 04 ), somatic symptoms (questions 05 to 10), decreased vital energy (questions 11 to 16 ), and depressive thoughts (questions 17 to 20). The response scale to each item is structured as yes/no, so that each positive response generates a point and the total score range between 0 and 20 (the higher the score, the worse the level of suspicion for common mental disorders). The sum of positive responses higher than 7 points indicates suspicion of CMD.

After the SRQ-20, the participant answered the following question: "Do you have swallowing disorders?" When the answer was "no" the volunteer's participation in the study ended at that point. When the answer was "yes", the Brazilian Portuguese version of the MD Anderson Dysphagia Inventory (MDADI) was subsequently applied ${ }^{25}$.

The MDADI is a specific instrument to evaluate the effects of swallowing disorders on the quality of life of patients who have undergone treatment for head and neck cancer. The MDADI consists of 20 items, the first of which is an overall question, while the others result into a total domain score. These 19 questions are subdivided into three domains: emotional domain (six questions), functional domain (five questions) and physical domain (eight questions), with scores ranging from 0 to 100 , with no cut-off point (the lower the score, the worse the effect of dysphagia on quality of life). Each question has five possible answers that are scored as follows: I totally agree (01 point); I agree (02 points); No opinion (03 points); I disagree (04 points); and I totally disagree (05 points). The score is inverse on item 02 of the functional domain ${ }^{25}$.

The overall MDADI question score ranges from 20 (extremely low functionality) to 100 (normal functionality). The scores for the emotional, physical and functional domains are the result of the ratio between the sum of the values of each domain question and the total number of domain questions, multiplied by 20 . To obtain the total domain score, the mean of the 19 items is multiplied by 20 . The result of the MDADI total domain also represents the self-reported limitation for swallowing according to the following classification: 0 to 20 - severe limitation; 21 to 40 - intense limitation; 41 to 60 - moderate limitation; $61-80$ - average limitation; 81-100 - minimum limitation ${ }^{26}$.

The MDADI were applied exclusively to those with swallowing complaint because it includes specific questions that can be answered only by people who previously reported a swallowing problem or have a current clinical diagnosis of dysphagia. Considering that the patients of this study generally consisted of people with low educational level, the application of all instruments was standardized as an interview.

The descriptive analysis of the numerical variables was carried out by calculating the measures of central tendency (mean and median) and variability (standard deviation and interquartile range), as well as the absolute and relative distribution of categorical variables. The non-parametric Mann-Whitney test was used to compare quantitative variables between groups. The level of significance was $5 \%$.

\section{RESULTS}

The characteristics of each patient, according to demographic and clinical variables, including SRQ-20 and MDADI domains, are shown in Table 1. 
Table 1. Sample characteristics according to demographic and clinical variables, including Self-Reported Questionnaire and M.D. Anderson Dysphagia Inventory domains $(n=14)$

\begin{tabular}{|c|c|c|c|c|c|c|c|c|c|c|c|c|c|c|c|}
\hline Patient & Age & Sex & Treatment & $\begin{array}{l}\text { Time } \\
\text { since } \\
\text { surgery }\end{array}$ & $\begin{array}{l}\text { SRQ-20 } \\
\text { Anxious } \\
\text { Depressive } \\
\text { Mood }\end{array}$ & $\begin{array}{c}\text { SRQ-20 } \\
\text { Somatic } \\
\text { Symptoms }\end{array}$ & $\begin{array}{c}\text { SRQ-20 } \\
\text { Decreased } \\
\text { Vital Energy }\end{array}$ & $\begin{array}{c}\text { SRQ-20 } \\
\text { Depressive } \\
\text { Thoughts }\end{array}$ & SRQ-20 Total & $\begin{array}{l}\text { Patient- } \\
\text { reported } \\
\text { swallowing } \\
\text { disorders }\end{array}$ & $\begin{array}{l}\text { MDADI } \\
\text { Emotional } \\
\text { Domain }\end{array}$ & $\begin{array}{l}\text { MDADI } \\
\text { Physical } \\
\text { Domain }\end{array}$ & $\begin{array}{l}\text { MDADI } \\
\text { Functional } \\
\text { Domain }\end{array}$ & $\begin{array}{l}\text { MDADI } \\
\text { Global }\end{array}$ & $\begin{array}{l}\text { MDADI } \\
\text { Total Score }\end{array}$ \\
\hline 1 & 70 & $M$ & Surg+RxT & 74 & 0 & 1 & 0 & 1 & 2 & No & NA & NA & NA & NA & NA \\
\hline 2 & 76 & $\mathrm{M}$ & $\mathrm{NI}$ & $\mathrm{NI}$ & 0 & 0 & 0 & 0 & 0 & No & NA & NA & NA & NA & NA \\
\hline 3 & 72 & $M$ & Surg +RxT & 188 & 0 & 3 & 1 & 0 & 4 & No & NA & NA & NA & NA & NA \\
\hline 4 & 71 & $\mathrm{M}$ & Surg +RxT & 56 & 1 & 2 & 0 & 0 & 3 & No & NA & NA & NA & NA & NA \\
\hline 5 & 62 & $\mathrm{M}$ & Surg +RxT & 96 & 0 & 0 & 0 & 0 & 0 & No & NA & NA & NA & NA & NA \\
\hline 6 & 60 & $M$ & Surg & 212 & 1 & 1 & 1 & 2 & 5 & No & NA & NA & NA & NA & NA \\
\hline 7 & 66 & $\mathrm{~F}$ & Surg + RxT & 131 & 0 & 0 & 0 & 0 & 0 & No & NA & NA & NA & NA & NA \\
\hline 8 & 55 & M & $\begin{array}{c}\text { Surg }+ \text { RxT } \\
\quad+\text { CT }\end{array}$ & 106 & 1 & 2 & 1 & 2 & 6 & No & NA & NA & NA & NA & NA \\
\hline 9 & 53 & M & Surg +RxT & 47 & 0 & 0 & 0 & 0 & 0 & No & NA & NA & NA & NA & NA \\
\hline 10 & 67 & $M$ & Surg + RxT & 17 & 1 & 1 & 0 & 1 & 3 & Yes & 53.3 & 70 & 60 & 40 & 61.1 \\
\hline 11 & 57 & $\mathrm{~F}$ & Surg + RxT & 82 & 0 & 1 & 1 & 2 & 4 & Yes & 86.6 & 80 & 68 & 100 & 78.2 \\
\hline 12 & 83 & $M$ & Surg + RxT & 138 & 1 & 1 & 1 & 2 & 5 & Yes & 63.3 & 77.5 & 76 & 20 & 72.2 \\
\hline 13 & 68 & $M$ & Surg +RxT & 94 & 1 & 3 & 1 & 4 & 9 & Yes & 33.3 & 55 & 60 & 40 & 49 \\
\hline 14 & 67 & M & $\mathrm{Nl}$ & $\mathrm{NI}$ & 0 & 2 & 0 & 0 & 2 & Yes & 33.3 & 60 & 52 & 100 & 48.4 \\
\hline \multicolumn{5}{|c|}{ Mean \pm SD } & $\begin{array}{c}0.43 \pm \\
0.51\end{array}$ & $\begin{array}{c}1.21 \pm \\
1.05\end{array}$ & $\begin{array}{c}0.43 \pm \\
0.51\end{array}$ & $\begin{array}{c}1.00 \pm \\
1.24\end{array}$ & $\begin{array}{c}3.07 \pm \\
2.67\end{array}$ & - & $\begin{array}{c}53.96 \pm \\
22.39\end{array}$ & $\begin{array}{c}68.50 \pm \\
10.83\end{array}$ & $\begin{array}{c}63.20 \pm \\
9.12\end{array}$ & $\begin{array}{c}60.00 \pm \\
37.41\end{array}$ & $\begin{array}{c}61.78 \pm \\
13.42\end{array}$ \\
\hline \multicolumn{5}{|c|}{ Minimum - maximum } & $0-1$ & $0-3$ & $0-1$ & $0-4$ & $0-9$ & - & $\begin{array}{c}33.30- \\
86.60\end{array}$ & $\begin{array}{c}55.00- \\
80.00\end{array}$ & $\begin{array}{c}52.00- \\
76.00\end{array}$ & $20-100$ & $\begin{array}{c}48.40- \\
78.20\end{array}$ \\
\hline \multicolumn{5}{|c|}{ Median (Q25-Q75) } & $\begin{array}{c}0.00 \\
(0.00-1.00)\end{array}$ & $\begin{array}{c}1.00 \\
(0.00-2.00)\end{array}$ & $\begin{array}{c}0.00 \\
(0.00-1.00)\end{array}$ & $\begin{array}{c}0.50 \\
(0.00-2.00)\end{array}$ & $\begin{array}{c}3.00 \\
(0.00-5.00)\end{array}$ & - & $\begin{array}{c}53.30 \\
(33.30- \\
74.95) \\
\end{array}$ & $\begin{array}{c}70.00 \\
(57.50- \\
78.75)\end{array}$ & $\begin{array}{c}60.00 \\
(56.00- \\
72.00) \\
\end{array}$ & $\begin{array}{c}40.00 \\
(30.00- \\
100.00)\end{array}$ & $\begin{array}{c}61.10 \\
(48.70- \\
75.20) \\
\end{array}$ \\
\hline
\end{tabular}

Captions: CT: chemotherapy; F: female; M: male; MDADI: M.D. Anderson Dysphagia Inventory; NA: not applicable; NI: not informed; RxT: radiotherapy; Surg: surgery; SRQ-20: Self-Reporting Questionnaire

The median of the SRQ-20 total score was below the cut-off point of the instrument ( $>7$ points) and was not enough to determine the CMD suspicion level in this sample (Table 1). The highest score was for somatic symptoms, followed by depressive thoughts. However, the scores were low with no clinical significance.

Five patients reported swallowing disorders and answered the MDADI. The result of the overall question of the MDADI revealed that after TL the patients perceived that the performance of their daily life activities was limited by their impaired swallowing ability. The median of the MDADI total score indicated that these patients had a moderate limitation of the swallowing function. The emotional domain had a lower median when compared to the physical and functional domains. Thus, these patients perceived that the negative impact of swallowing disorders was higher in the emotional aspects related to the quality of life.

The SRQ-20 scores were compared between the groups with and without self-reported swallowing disorders (Table 2). Although the relationship was not significant and the level of suspicion of CMD was not found, the median scores of all SRQ-20 domains were higher in the group with self-reported swallowing disorders.

Table 2. Self-Reporting Questionnaire scores in patients with and without self-reported swallowing disorders $(n=14)$

\begin{tabular}{lccc}
\hline \multirow{2}{*}{ SRQ-20 domains } & \multicolumn{2}{c}{ Patient-reported swallowing disorders } & \\
\cline { 2 - 3 } & \multicolumn{2}{c}{ Yes $\mathbf{( n = 0 5 )}$} & No $\mathbf{~} \mathbf{n}=\mathbf{0 9})$ \\
\cline { 2 - 3 } & \multicolumn{2}{c}{ Median (Q25-075) } & 0.15 \\
\hline Total & $4.60 \pm 2.70$ & $2.22 \pm 2.38$ & 0.35 \\
Anxious Depressive Mood & $0.60 \pm 0.54$ & $0.33 \pm 0.50$ & 0.26 \\
Somatic Symptoms & $1.60 \pm 0.89$ & $1.00 \pm 1.11$ & 0.35 \\
Decreased Vital Energy & $0.60 \pm 0.54$ & $0.33 \pm 0.50$ & 0.08 \\
Depressive Thoughts & $1.80 \pm 1.48$ & $0.56 \pm 0.88$ & \\
\hline
\end{tabular}

Caption: SRQ-20: Self-Reporting Questionnaire; $p<0,05$. Mann-Whitney test. 


\section{DISCUSSION}

The results of this study indicated absence of CMD after long-term TL. Although the SRQ-20 scores were increased in the group of swallowing complaints, this relationship was not significant. TL patients who reported impaired swallowing perceived negative impact on quality of life, especially on emotional domain.

The characteristics of this sample is similar to other studies $^{19,20}$. It is possible that the absence of CMD could be justified by some of these characteristics, such as the higher proportion of men in the sample. The prevalence of CMD is higher in women ${ }^{24}$, but this study only had two female participants.

The literature states that worse socioeconomic conditions increase the risk of $\mathrm{CMD}^{27}$. At the same time, it reports that patients with low education have fewer psychological problems ${ }^{21}$ and that social support is a factor that reduces the risk of CMD, either through healthcare networks or through insertion and participation in support groups ${ }^{28}$. In this study, it is believed that although the patients had low socioeconomic conditions, the low education level and social support found in weekly group activities may have at least partially mitigated the interference of socioeconomic conditions in the onset of CMD.

Still regarding the absence of CMD in the sample of this study, it is possible to presume other hypotheses. Although the evidence is controversial ${ }^{15}$, coping strategies focused on spirituality and religiosity as emotional regulators may represent denial or elusive attitudes to cope with the health condition in the face of stressful events such as cancer. This relationship, possibly intrinsic to situations of emotional pain, is often confused with "pessimism" or "negative thoughts", which may lead to situations of omission due to the structure of organizations based on the idea of belief.

However, coping strategies based on spirituality and religiosity have already shown a positive relationship with improvement in quality of life in cancer patients $\mathbf{s}^{22,29,30}$. These forms of coping can be internalized as the main sources of curing cancer, and once the disease is stabilized, the patient can minimize other possible associated physical and psychological sequelae.

It is also necessary to consider that the low level of CMD after total laryngectomy may be related to the subjects' possible difficulty in reporting emotional pain either to people who do not participate in their daily lives and/or to others who accompany them regularly throughout the treatment ${ }^{31}$. In the first situation, the embarrassment or fear of exposing themselves to strangers may lead the patient to omit or deny what they feel. In the second situation, there may be a desire to show firmness towards the treatment and to not frustrate those who are most often by their side, whether they belong to their personal circle or the health team.

Other study in Germany found that 22\% of TL patients had mental disorders, however, it was during the first year after the surgery and the instrument for data acquisition was a structured clinical interview ${ }^{32}$. It is noteworthy that the sample of this study was composed of patients of another culture who answered SRQ-20 after an average time of eight years since the surgery.

Even though there was no significant relationship, it was observed that all SRQ-20 mean scores were lower in patients with self-reported swallowing disorders. It is known that the fear of swallowing disorders increases the psychological suffering and limit the accomplishment of social activities related to eating ${ }^{10}$. In addition, irreversible loss of laryngeal voice, definitive tracheostoma and aesthetic disfiguration increases the negative impact of total laryngectomy on the emotional status ${ }^{20}$.

In cancer patients, psychological well-being may be compromised at the time of diagnosis and/or after treatment ${ }^{33}$. Therefore, feelings of disability and fear is not uncommon during the disease, which helps to explain the predominance of the negative impact of difficulty to swallow in the emotional domain of MDADI in this sample.

The emotions, feelings, burden of distress, worry, anxiety and level of satisfaction with the health condition are part of the psychological well-being ${ }^{34}$. Therefore, the difficulty to swallow after total laryngectomy may not only be related to structural impairment, but also to the emotional component, with episodes of frustration and worry ${ }^{35}$ related to their own capacity, whose significant impact on functionality directly interferes with the quality of life of this population in a negative way.

Instead of what was found in this sample, the physical domain score of MDADI was the most impaired in previous studies with patients after total laryngectomy $8,36,37$. However, it should be considered that the sample size that answered to the MDADI in this study was small, constituting a bias.

Another highlight of this study is that the impact of TL may be late in some subjects, which calls attention to the need for long-term follow-up ${ }^{38}$ including screening 
tools to capture the patient's real impression of their swallowing or mental disorders to provide healthcare for psychosomatic illness and a better quality of life.

This study has some limitations. The sample size may have interfered in some results due to the low representativeness of individuals with self-reported swallowing disorders and with higher scores in the $\mathrm{SRQ}-20$. Future multicenter research may minimize these biases. Better analysis on the role of the support group in the studied variables, which could be done by replicating the investigation including patients with more restricted social support, is also suggested. Although there are such limitations, this study is the first to investigate the relationship between swallowing and CMD (other than depression and anxiety) following TL. The results highlight some preliminary data for further studies and express situations that need to be better clarified to become applicable in the care of these patients.

\section{CONCLUSION}

This study suggests that CMD and patient-reported swallowing disorders, following TL, are not related in the long-term, although the number of psychological symptoms is increased in patients with swallowing complaints. The impact of self-reported swallowing disorders was higher on emotional domains related to the quality of life.

\section{REFERENCES}

1. Zhang $T$, Szczesniak M, Maclean J, Bertrand $P$, Wu PI, Omari T et al. Biomechanics of pharyngeal deglutitive function following total laryngectomy. Otolaryngol Head Neck Surg. 2016;155(2):295-302.

2. Harris BN, Hoshal SG, Evangelista L, Kuhn M. Reconstruction technique following total laryngectomy affects swallowing outcomes. Laryngoscope Investig Otolaryngol. 2020;5(4):703-7.

3. Maclean J, Cotton S, Perry A. Post-laryngectomy: it's hard to swallow. Dysphagia. 2009;24(2):172-9.

4. Coffey MM, Tolley N, Howard D, Drinnan M, Hickson M. An investigation of the post-laryngectomy swallow using videofluoroscopy and Fiberoptic Endoscopic Evaluation of Swallowing (FEES). Dysphagia. 2018;33(3):369-79.

5. Buá BA, Pendleton H, Westin U, Rydell R. Voice and swallowing after total laryngectomy. Acta Otolaryngol. 2018;138(2):170-4.
6. Coffey M, Tolley N. Swallowing after laryngectomy. Curr Opin Otolaryngol Head Neck Surg. 2015;23(3):202-8.

7. Lippert D, Hoffman MR, Britt CJ, Jones CA, Hernandez J, Ciucci MR et al. Preliminary evaluation of functional swallow after total laryngectomy using high-resolution manometry. Ann Otol Rhinol Laryngol. 2016;125(7):541-9.

8. Danker H, Wollbrück D, Singer S, Fuchs M, Brähler E, Meyer A. Social withdrawal after laryngectomy. Eur Arch Otorhinolaryngol. 2010;267(4):593-600.

9. Shuman AG, Larkin K, Thomas D, Palmer FL, Fins JJ, Baxi SS et al. Patient reflections on decision making for laryngeal cancer treatment. Otolaryngol Head Neck Surg. 2017;156(2):299-304.

10. Verdonschot RJCG, Baijens LWJ, Serroyen JL, Leue C, Kremer B. Symptoms of anxiety and depression assessed with the Hospital Anxiety and Depression Scale in patients with oropharyngeal dysphagia. J Psychosom Res. 2013;75(5):451-5.

11. Kemps GJF, Krebbers I, Pilz W, Vanbelle S, Baijens LWJ. Affective symptoms and swallow-specific quality of life in total laryngectomy patients. Head Neck. 2020;42(11):3179-87.

12. Wulff NB, Dalton SO, Wessel I, Arenaz Búa B, Löfhede $\mathrm{H}$, Hammerlid $\mathrm{E}$ et al. Health-related quality of life, dysphagia, voice problems, depression, and anxiety after total laryngectomy. Laryngoscope. 2021; Sep 7. Epub ahead of print.

13. Chan JYK, Lua LL, Starmer HH, Sun DQ, Rosenblatt ES, Gourin CG. The relationship between depressive symptoms and initial quality of life function in head and neck cancer. Laryngoscope. 2011;121(6):1212-28.

14. Lin BM, Starmer HM, Gourin CG. The relationship between depressive symptoms, quality of life, and swallowing function in head and neck cancer patients 1 year after definitive therapy. Laryngoscope. 2012;122(7):1518-25.

15. Morris N, Moghaddam N, Tickle A, Biswas S. The relationship between coping style and psychological distress in people with head and neck cancer: a systematic review. Psychooncology. 2018;27(3):734-7.

16. American Psychiatric Association. Diagnostic and Statistical Manual of Mental Disorders, Fifth Edition (DSM-V). Vancouver, Canada: American Psychiatric Association; 2013.

17. Gomes VF, Miguel TLB, Miasso Al. Common mental disorders: socio-demographic and 
pharmacotherapy profile. Rev Latino-Am Enfermagem. 2013;21(6):1203-11.

18. Fonseca MLG, Guimarães MBL, Vasconcelos EM. Diffuse suffering and common mental disorders: a literature review. Rev APS. 2008;11(3):285-94.

19. Pernambuco $L$ de $A$, Oliveira $J H$, Régis RM, Lima LM, Araújo AM, Balata PM et al. Quality of life and deglutition after total laryngectomy. Int Arch Otorhinolaryngol. 2012;16(4):460-5.

20. Maclean J, Cotton S, Perry A. Dysphagia following a total laryngectomy: the effect on quality of life, functioning, and psychological well-being. Dysphagia. 2009;24(3):314-21.

21. Tian L, An R, Zhang J, Sun Y, Zhao R, Liu M. Effect of the patient-to-patient communication model on dysphagia caused by total laryngectomy. J Laryngol Otol. 2017;131(3):253-8.

22. Bai M, Lazenby M. A systematic review of associations between spiritual well-being and quality of life at the scale and factor levels in studies among patients with cancer. $\mathrm{J}$ Palliat Med. 2015;18(3):286-98.

23. Mari JJ, Williams P. A comparison of the validity of two psychiatric screening questionnaires (GHQ-12 and SRQ-20) in Brazil, using Relative Operating Characteristic (ROC) analysis. Psychol Med. 1985;15(3):651-9.

24. Santos KOB, Araújo TM, Pinho PS, Silva ACC. Evaluation of an instrument for measuring psychiatric morbidity: a validity study of the Self-Reporting Questionnaire (SRQ-20). Rev Baiana Saúde Pública. 2010;34(3):544-60.

25. Guedes RL, Angelis EC, Chen AY, Kowalski LP, Vartanian JG. Validation and application of the M.D. Anderson Dysphagia Inventory in patients treated for head and neck cancer in Brazil. Dysphagia. 2013;28(1):24-32.

26. Chen PH, Golub JS, Hapner ER, Johns MM 3rd. Prevalence of perceived dysphagia and quality-of-life impairment in a geriatric population. Dysphagia. 2009;24(1):1-6.

27. Araújo TM, Pinho PS, Almeida MMG. Prevalence of psychological disorders among women according to socio demographic and housework characteristics. Rev bras saude mater infant. 2005;5(3):337-48.

28. Costa AG, Ludemir AB. Common mental disorders and social support in a rural community in Zona da Mata, Pernambuco state, Brazil. Cad Saúde Pública. 2005;21(1):73-9.
29. Whitford HS, Olver IN, Peterson MJ. Spirituality as a core domain in the assessment of quality of life in oncology. Psychooncology. 2008;17(11):1121-8.

30. Gonzalez P, Castañeda SF, Dale J, Medeiros EA, Buelna $C$, Nuñez $A$ et al. Spiritual well-being and depressive symptoms among cancer survivors. Support Care Cancer. 2014;22(9):2393-400.

31. Northhouse LL, KAtapodi MC, Song L, Zhang L, Mood DW. Interventions with family caregivers of cancer patients: meta-analysis of randomized trials. Ca Cancer J Clin. 2010;60(5):317-39.

32. Keszte J, Danker H, Dietz A, Meister E, Pabst F, Vogel HJ et al. Mental disorders and psychosocial support during the first year after total laryngectomy: a prospective cohort study. Clin Otolaryngol. 2013;38(6):494-501.

33. Baijens LWJ, Koetsenruijter K, Pilz W. Diagnosis and treatment of phagophobia: a review. Dysphagia. 2013;28(2):260-70.

34. Gil F, Costa G, Hilker I, Benito L. First anxiety, afterwards depression: psychological distress in cancer patients at diagnosis and after medical treatment. Stress Health. 2012;28(5):362-7.

35. Enderby P, John A, Petheram B. Therapy outcome measures for rehabilitation professionals: speech and language therapy, physiotherapy, occupational therapy. 2th ed. New Jersey, USA: John Wiley \& Sons; 2013.

36. Kazi R, Prasad V, Venkitaraman R, Nutting CM, Clarke $P$, Rhys-Evans $P$ et al. Questionnaire analysis of the swallowing-related outcomes following total laryngectomy. Clin Otolaryngol. 2006,31(6):525-30.

37. Robertson SM, Yeo JCL, Dunnet C, Young D, MacKenzie K. Voice, swallowing, and quality of life after total laryngectomy - results of the West of Scotland Laryngectomy Audit. Head Neck. 2012;34(1):59-65.

38. Ward EC, Bishop B, Frisby J, Stevens M. Swallowing outcomes following laryngectomy and pharyngolaryngectomy. Arch Otolaryngol Head Neck Surg. 2002;128(2):181-6. 